\title{
Baseline characteristics of depressive disorders in Thai outpatients: findings from the Thai Study of Affective Disorders
}

This article was published in the following Dove Press journal:

Neuropsychiatric Disease and Treatment

31 January 2014

Number of times this article has been viewed

\begin{abstract}
Tinakon Wongpakaran'
Nahathai Wongpakaran'

Manee Pinyopornpanish'

Usaree Srisutasanavong'

Peeraphon Lueboonthavatchai ${ }^{2}$

Raviwan Nivataphand ${ }^{2}$

Nattaporn Apisiridej ${ }^{3}$

Donruedee Petchsuwan ${ }^{3}$

Nattha Saisavoey ${ }^{4}$

Kamonporn Wannarit ${ }^{4}$

Ruk Ruktrakul ${ }^{5}$

Thawanrat Srichan ${ }^{5}$

Sirina Satthapisit ${ }^{6}$

Daochompu Nakawiro ${ }^{7}$

Thanita Hiranyatheb ${ }^{7}$

Anakevich Temboonkiat ${ }^{8}$

Namtip Tubtimtong ${ }^{9}$

Sukanya Rakkhajeekul ${ }^{9}$

Boonsanong Wongtanoi ${ }^{10}$

Sitthinant Tanchakvaranont ${ }^{\prime \prime}$

Putipong Bookkamana ${ }^{12}$

'Faculty of Medicine, Chiang Mai University, Chiang Mai, ${ }^{2}$ Faculty of Medicine,

Chulalongkorn University, Bangkok, ${ }^{3}$ Trang

Hospital, Trang, ${ }^{4}$ Faculty of Medicine, Siriraj

Hospital, Mahidol University, Bangkok,

${ }^{5}$ Lampang Hospital, Lampang, ${ }^{6} \mathrm{~K}$ honKaen

Hospital, Khon Kaen, ${ }^{7}$ Faculty of Medicine,

Ramathibodi Hospital, Mahidol University,

Bangkok, ${ }^{8}$ Phramongkutklao Hospital,

Bangkok, ${ }^{9}$ Faculty of Medicine Naresuan

University, Pitsanulok, ${ }^{10}$ Srisangwal Hospital,

Mae Hong Son, "Queen Savang Vadhana

Memorial Hospital, Chonburi, ${ }^{12}$ Faculty of

Science, Chiang Mai University, Chiang Mai

Kingdom of Thailand
\end{abstract}

Correspondence: Tinakon Wongpakaran

Department of Psychiatry, Faculty of

Medicine, Chiang Mai University,

I I 0 Intawarorot Rd, Tambon Sriphum,

Amphur Muang, Chiang Mai, Thailand 50200

Tel +6653945422

Fax +66 53945426

Email tinakon.w@cmu.ac.th
Background: The Thai Study of Affective Disorders was a tertiary hospital-based cohort study developed to identify treatment outcomes among depressed patients and the variables involved. In this study, we examined the baseline characteristics of these depressed patients.

Methods: Patients were investigated at eleven psychiatric outpatient clinics at tertiary hospitals for the presence of unipolar depressive disorders, as diagnosed by the Diagnostic and Statistical Manual of Mental Disorders, Fourth Edition. The severity of any depression found was measured using the Clinical Global Impression and 17-item Hamilton Depression Rating Scale (HAMD) clinician-rated tools, with the Thai Depression Inventory (a self-rated instrument) administered alongside them. Sociodemographic and psychosocial variables were collected, and quality of life was also captured using the health-related quality of life (SF-36v2), EuroQoL (EQ-5D), and visual analog scale (EQ VAS) tools.

Results: A total of 371 outpatients suffering new or recurrent episodes were recruited. The mean age of the group was $45.7 \pm 15.9$ (range 18-83) years, and $75 \%$ of the group was female. In terms of diagnosis, $88 \%$ had major depressive disorder, $12 \%$ had dysthymic disorder, and $50 \%$ had a combination of both major depressive disorder and dysthymic disorder. The mean (standard deviation) scores for the HAMD, Clinical Global Impression, and Thai Depression Inventory were $24.2 \pm 6.4,4.47 \pm 1.1$, and $51.51 \pm 0.2$, respectively. Sixty-two percent had suicidal tendencies, while $11 \%$ had a family history of depression. Of the major depressive disorder cases, 61\% had experienced a first episode. The SF-36v2 component scores ranged from 25 to 56, while the mean (standard deviation) of the EQ-5D was $0.50 \pm 0.22$ and that of the EQ VAS was $53.79 \pm 21.3$.

Conclusion: This study provides an overview of the sociodemographic and psychosocial characteristics of patients with new or recurrent episodes of unipolar depressive disorders.

Keywords: baseline characteristics, depressive disorder, Thailand, treatment outcome, prospective cohort

\section{Introduction}

Depression causes a significant number of years of life lost due to disability in Thailand, and ranks behind only cardiovascular disorder, human immunodeficiency virus/ acquired immunodeficiency syndrome, and diabetes mellitus on the disability-adjusted life year index (1999-2004). ${ }^{1}$ The Epidemiology of Mental Disorders National Survey in 2008 found major depressive disorder (MDD) in 3.2\% of the Thai population, while $0.3 \%$ were found to have dysthymia (double depression was not reported). ${ }^{2}$ Despite the serious impact this disorder can have, no study has ever been published, to the authors' knowledge, regarding treatment outcomes. Psychosocial factors usually play an important role in relation to depression, either as predisposing or precipitating 
elements, and so have an impact on treatment outcomes. In this study, we focused on insecure attachment (which is related to the vulnerability of an individual's personality) and interpersonal problems among sample patients, because both are viewed as predisposing factors with respect to depression. The key precipitating factors found in this study were individual perceptions of stress and lack of social support. Prior studies have shown that insecure attachment can be related to depression, and especially fearful attachment, which has been found to be both a predictor of recurrent depression and to delay recovery. ${ }^{3,4}$ Likewise, interpersonal problems, and particularly social inhibition, have been found to be associated with depression, as has the perception of being stressed. ${ }^{5-7}$ However, the perceived level of social support received has been inconsistently related to depression in the research studies carried out; inconsistency has not only occurred with respect to depression outcomes, but also quality of life outcomes. ${ }^{8,9-16}$

Previous studies showed that quality of life was related to the severity of depression, and improvement as the symptoms subsided. ${ }^{17-20}$ Factors predicting quality of life in people suffering from acute depression include the severity of depression and economic problems, while family problems, duration of depression experienced, and its severity were found to be related to quality of life in those with chronic depression. $^{21}$

To examine these associated factors and outcomes, we carried out the Thai Study of Affective Disorder (Thai-SAD), a one-year observational, collaborative, prospective cohort study of treatment outcomes in patients with MDD and/or dysthymic disorder, as well as patient quality of life. The research consisted of a multicenter study carried out at psychiatric outpatient clinics at tertiary hospitals (university and provincial hospitals) throughout Thailand, using newly diagnosed or referred cases from community hospitals and primary care settings. The purpose of this paper is to present the baseline sociodemographic and psychosocial characteristics of the study participants.

\section{Materials and methods}

\section{Participants and procedures}

A prospective, longitudinal follow-up study was carried out over the period March 2011 to August 2012 in 346 enrolled outpatients diagnosed with MDD, dysthymic disorder, or double depressive disorder, who were receiving standard treatment from a multidisciplinary team of psychiatrists, psychologists, and social workers at eleven tertiary hospitals across Thailand.
The study period lasted one year at each of the sites, although the whole study took 17 months due to the varying start times. Eligible participants were aged 18 years or older, had presented with symptoms to an outpatient clinic, and had then screened positive for depression when using the two-question (depressed mood and/or loss of interest) screening questionnaire, had experienced a first episode of MDD or recurrent episodes, and/or recurrent episodes of dysthymia or double depression. Exclusion criteria were: comorbidity, pregnancy, and lactation; severe substance abuse; cognitive impairment on Mini-Mental Status Examination; a history of schizophrenia or bipolar disorder; and failure to provide written informed consent.

At baseline, the participants were diagnosed as having MDD and/or dysthymic disorder according to the Diagnostic and Statistical Manual of Mental Disorders, Fourth Edition, Text Revision (DSM-IV-TR) using the Mini International Neuropsychiatric Inventory (MINI), ${ }^{22,23}$ and were also assessed for depression by trained clinicians and psychiatric investigators. Demographic data and psychosocial variables, as reported by the participants, were then collected by research assistants. The participants were followed up at 3-month intervals over a one-year period (five assessments, including baseline). The 17-item Hamilton Depression Rating Scale (HAMD-17) and Clinical Global Impression (CGI) were evaluated by investigators at each visit; however, a complete set of measurements (all using clinician-rated and self-reporting questionnaires) was carried out three times; first at baseline, the second time at visit 3, and the third time at visit 5.

Of the 3,167 outpatients being treated for MDD across all eleven hospitals at the time of the study, 371 (11.7\%) cases with a new episode or recurrent episodes of unipolar MDD, dysthymic disorder, and/or double depression gave their consent and were recruited. Twenty-five of these potential participants were excluded due to the presence of comorbidity, meaning the final study included 346 patients.

\section{Instruments}

The clinician-rated measurement tools used included the Clinical Global Impression-Severity scale (CGI-S), a sevenpoint scale that requires clinicians to rate severity of illness (1, normal; 7, extremely ill). The severity of depression was assessed using the HAMD-17, plus a self-reporting depression scale which included the Thai Depression Inventory (TDI), a 20-item, four-rating scale which assesses the severity of depressive symptoms (1, most severe; 4 , normal). The TDI was used for patients aged $18-59$ years. The Thai 
versions of the HAMD and TDI demonstrate good reliability and validity. ${ }^{24,25}$ The Thai version of the Geriatric Depression Scale, a 30-item, true-false type assessment of depressive symptoms, was also used for participants aged $\geq 60$ years, and has also demonstrated good reliability and validity. ${ }^{26}$

Additional outcome measures included those related to quality of life. The 36-item health-related quality of life (SF-36v2) tool was used to elicit eight quality of life components, including general health, physical functioning, role-physical, role-emotional, social functioning, bodily pain, vitality, and mental health, as was the EuroQoL-5 Dimension (EQ-5D), a five-item standardized questionnaire used to assess five quality of life aspects, these being mobility, self-care, usual activities, pain/discomfort, and anxiety/depression. The Thai version has demonstrated good reliability. In addition to the EQ-5D descriptive system, respondents rated their health at the time using a visual analog scale (EQ VAS) ranging from 0 (worst imaginable health state) to 100 (best imaginable health state). The Thai version of the EQ-5D has been validated in the general Thai population. ${ }^{27,28}$

The psychosocial measurement tools used included the 32-item Inventory of Interpersonal Problems scale, which uses a 5-Likert scale to assess the severity of eight aspects of interpersonal problems experienced throughout the participants' daily lives. These interpersonal problems include dominance, vindictiveness, cold, social inhibition, nonassertiveness, over-accommodation, self-sacrifice, and intrusion. The Thai version of the 32-item Inventory of Interpersonal Problems scale has demonstrated good reliability and validity. ${ }^{29}$ Secure and insecure attachment were assessed using the short version of the Revised-Experience of Close Relationships scale, a 18-item, 7-Likert scale tool which assesses how much anxiety (ie, attachment anxiety) or how close the respondent feels towards a partner or person close to them (ie, attachment avoidance). High attachment anxiety and/or high attachment avoidance is considered to reflect insecure attachment. The Thai version of the Revised-Experience of Close Relationships scale has also demonstrated good reliability and validity. ${ }^{29,30}$ Also used were the Perceived Stress Scale (PSS), a 10-item scale, 5-Likert scale tool which records how frequently people feel stressed, and the Multi-dimensional Scale of Perceived Social Support (MSPSS), a 12-item, 7-Likert scale self-reporting tool which records how much social support respondents require. The Thai versions of the PSS and MSPSS have demonstrated good reliability and validity. ${ }^{31-33}$

\section{Statistical analysis}

For the continuous variables, the mean \pm standard deviations (SD) and median with range were used, whereas categorical data were presented as the number and percentage. The statistical significance level for all the tests was set at a $P$-value $<0.05$, and Statistical Package for the Social Sciences version 17 software (SPSS Inc., Chicago, IL, USA) was used to perform all the analyses.

\section{Results}

Table 1 shows that the mean \pm SD participant age was $45.7 \pm 15.9$ (range 18-83) years. Seventy-five percent of respondents were female, and $42(12.1 \%)$ had been educated to elementary school level or less. In terms of marital status, 109 (32.3\%) were single, while for employment status, most were employed (75.7\%). Two hundred and four (62.2\%) earned no more than 10,000 baht (US\$300) per month, while $39.9 \%$ earned less than 5,000 baht (US\$166.7). Two hundred and twenty-six (79.4\%) had government-related health insurance.

With respect to the diagnoses, MDD was diagnosed in $88.4 \%$ of the sample, with $61.4 \%$ having a first episode of MDD. Nearly $12 \%$ of the group was suffering from dysthymic disorder, while nearly $50 \%$ had superimposed MDD (double depression). The mean \pm SD scores on the HAMD for MDD, dysthymic disorder, and double depression were $24.20 \pm 6.4,19.90 \pm 6.4$, and 25.06 \pm 4.6 , respectively.

The mean \pm SD CGI score was $4.47 \pm 1.1$. There was a high incidence of suicidality found in 207 of the group $(62.3 \%)$, with $51.7 \%$ suffering a moderate to severe level. Eighty respondents $(26.5 \%)$ had a history of suicide attempts, whereas $29.2 \%$ had a family history of a psychiatric disorder. Among those with a family history of a psychiatric disorder, a history of depression was prevalent (10.7\%).

In terms of psychosocial factors, the mean \pm SD for the 32-item Inventory of Interpersonal Problems scale, attachment anxiety, attachment avoidance, PSS, and MSPSS was $65.8 \pm 13.3,3.72 \pm 1.6,3.88 \pm 1.1,19.22 \pm 5.3$, and 4.38 \pm 1.3 , respectively. The percentage of those demonstrating secure attachment was higher than for insecure attachment (80.6\% versus $19.4 \%$ ).

For quality of life, the subscale scores using the SF-36v2 ranged from 25.35 to 55.60. The subscale for general health received the lowest score $(25.35 \pm 18.20)$, while physical role received the highest score $(55.60 \pm 28.3)$.

The mean score generated by the EQ-5D tool for the total sample was $0.502 \pm 0.22$, and this corresponded with the 
Table I Baseline characteristics of respondents with depression

\begin{tabular}{|c|c|}
\hline $\begin{array}{l}\text { Sociodemographic } \\
\text { variables }(n=346)\end{array}$ & $\begin{array}{l}\text { Value } \\
\text { n (\%) or mean (SD) }\end{array}$ \\
\hline \multicolumn{2}{|l|}{ Sex } \\
\hline Male & $87(25.14)$ \\
\hline Female & $259(74.56)$ \\
\hline \multicolumn{2}{|l|}{ Age (years) } \\
\hline $18-30$ & $74(2 \mid .4)$ \\
\hline $31-45$ & $101(29.2)$ \\
\hline $46-59$ & $106(30.6)$ \\
\hline$\geq 60$ & $65(18.8)$ \\
\hline Mean (SD) & 45.7 (I5.9) \\
\hline Median (range) & $45(18-83)$ \\
\hline \multicolumn{2}{|l|}{ Education } \\
\hline Below elementary & $42(12.1)$ \\
\hline Elementary to junior high school & $105(30.3)$ \\
\hline High school & $79(22.8)$ \\
\hline Bachelor degree or higher & $120(34.7)$ \\
\hline \multicolumn{2}{|l|}{ Marital status } \\
\hline Single & $109(31.5)$ \\
\hline Married & $154(45.5)$ \\
\hline Widowed/divorced & $83(24.0)$ \\
\hline \multicolumn{2}{|l|}{ Employment } \\
\hline Employed & $262(75.7)$ \\
\hline Unemployed & $84(24.3)$ \\
\hline \multicolumn{2}{|l|}{ Income (baht) } \\
\hline$<5,000$ & |3| (37.9) \\
\hline $5,001-10,000$ & $73(21.1)$ \\
\hline $10,001-20,000$ & $65(18.8)$ \\
\hline$>20,000$ & $59(22.2)$ \\
\hline \multicolumn{2}{|l|}{ Health care delivery system used } \\
\hline Self-financed & $69(19.9)$ \\
\hline Civil servant medical benefits scheme & $100(28.9)$ \\
\hline Social security scheme & $50(14.5)$ \\
\hline Universal coverage scheme & $127(36.7)$ \\
\hline \multicolumn{2}{|l|}{ Depression } \\
\hline MDD (both first episode and recurrent) & $306(88.4)$ \\
\hline Dysthymic disorder & $22(6.4)$ \\
\hline Double depression & $18(5.2)$ \\
\hline \multicolumn{2}{|l|}{$\operatorname{MDD}(n=306)$} \\
\hline First episode & $188(61.4)$ \\
\hline Recurrent episodes & $118(38.6)$ \\
\hline MDD with psychotic symptoms & $15(4.3)$ \\
\hline MDD with melancholic symptoms & $124(35.8)$ \\
\hline \multicolumn{2}{|l|}{ Suicidality present $(n=332)$} \\
\hline Yes & $207(62.3)$ \\
\hline No & $125(37.7)$ \\
\hline \multicolumn{2}{|l|}{ Severity of suicidality } \\
\hline Mild (score I-5) & $98(48.3)$ \\
\hline Moderate (score 6-9) & $34(16.7)$ \\
\hline Severe (score $\geq 10$ ) & $71(35.0)$ \\
\hline \multicolumn{2}{|l|}{ Measurement of depression } \\
\hline \multicolumn{2}{|l|}{ HAMD-17 } \\
\hline Total mean (SD) & $24.20(6.4)$ \\
\hline (Range) & $(10-43)$ \\
\hline $\operatorname{MDD}(n=306)$ & $24.40(6.6)$ \\
\hline Dysthymic disorder $(n=22)$ & $19.90(6.4)$ \\
\hline Double depression $(n=18)$ & $25.06(4.6)$ \\
\hline
\end{tabular}

Table I (Continued)

\begin{tabular}{|c|c|}
\hline $\begin{array}{l}\text { Sociodemographic } \\
\text { variables }(n=346)\end{array}$ & $\begin{array}{l}\text { Value } \\
\text { n (\%) or mean (SD) }\end{array}$ \\
\hline $\begin{array}{l}\text { Thai Depression Inventory }(\mathrm{n}=272) \\
\text { (Range) }\end{array}$ & $\begin{array}{l}51.51(10.2) \\
(28-80)\end{array}$ \\
\hline $\begin{array}{l}\text { Geriatric Depression Scale }(\mathrm{n}=74) \\
\quad \text { (Range) }\end{array}$ & $\begin{array}{l}17.77(6.8) \\
(3-29)\end{array}$ \\
\hline \multicolumn{2}{|l|}{ CGI-S } \\
\hline Mean (SD) & $4.47(\mathrm{I} . \mathrm{I})$ \\
\hline Median (range) & $5.0(2.0-7.0)$ \\
\hline \multicolumn{2}{|l|}{ History of suicide attempts $(n=302)$} \\
\hline Yes & $80(26.5)$ \\
\hline No & $222(73.5)$ \\
\hline \multicolumn{2}{|c|}{ Family history of psychiatric disorders $(n=328)$} \\
\hline Yes & $96(29.2)$ \\
\hline No & $232(70.8)$ \\
\hline \multicolumn{2}{|l|}{ Family history } \\
\hline Depression & $35(10.7)$ \\
\hline Bipolar disorder & $5(1.5)$ \\
\hline Cognitive disorder & $4(1.2)$ \\
\hline Alcohol and substance disorders & $8(2.3)$ \\
\hline $\begin{array}{l}\text { Other (schizophrenia, autism, } \\
\text { anxiety disorders) }\end{array}$ & $42(12.8)$ \\
\hline
\end{tabular}

Abbreviations: CGI-S, Clinical Global Impression of Severity; MDD, major depressive disorder; SD, standard deviation; HAMD-17, 17-item Hamilton Depression Rating Scale.

mean score produced by the EQ VAS, which was $50.86 \pm 21.5$, reflecting a moderate quality of life score (Table 2).

\section{Discussion}

As found in other studies, women sought treatment for depression more readily than men. For example, in a Canadian and US national survey, the ratio of females to males seeking treatment was 1.64-1.67:1, which is consistent with a previous national survey in Thailand where the ratio was 1.6:1., 2,34,35 However, for our study, carried out in a university or provincial hospital setting, this ratio rose to 2.97:1, when hospitals are considered tertiary care settings where patients can access treatment either directly or via referral. This figure is similar to that reported for South Korea by Kim et al, who found a ratio of 2.91:1. ${ }^{36}$ This may be due to the fact that depressed Asian men are less likely to seek help than depressed Asian women. ${ }^{37-39}$ In addition, when comparing our age group results with those in that study, we found a similarly high proportion of elderly patients, ie, $18.8 \%$ (14.5\% over 65 years of age) as compared with $16.7 \%$ (aged 65 years and over) in South Korea. The ratio found for this age group was, therefore, higher in this study than in previous Thai studies.

In terms of the distribution of diagnoses, the rate of dysthymia in our study was quite low when compared with 
Table 2 Psychosocial variables and quality of life components

\begin{tabular}{|c|c|}
\hline & $\begin{array}{l}\text { Value } \\
\text { n (\%) or mean (SD) }\end{array}$ \\
\hline \multicolumn{2}{|l|}{ Psychosocial variables $(n=346)$} \\
\hline $\begin{array}{l}\text { Interpersonal problems } \\
\text { (Range) }\end{array}$ & $\begin{array}{l}65.82(13.3) \\
(25-105)\end{array}$ \\
\hline $\begin{array}{l}\text { Attachment anxiety } \\
\text { (Range) }\end{array}$ & $\begin{array}{l}3.72(1.6) \\
(I-7)\end{array}$ \\
\hline $\begin{array}{l}\text { Attachment avoidance } \\
\text { (Range) }\end{array}$ & $\begin{array}{l}3.88(1.1) \\
(1-7)\end{array}$ \\
\hline \multicolumn{2}{|l|}{ Insecure attachment $(n=325)$} \\
\hline Yes & $63(19.4)$ \\
\hline No & $262(80.6)$ \\
\hline $\begin{array}{l}\text { Perceived stress } \\
\quad \text { (Range) }\end{array}$ & $\begin{array}{l}19.22(5.3) \\
(2-32)\end{array}$ \\
\hline $\begin{array}{l}\text { Multidimensional scale for social support } \\
\text { (Range) }\end{array}$ & $\begin{array}{l}4.38(1.3) \\
(I-7)\end{array}$ \\
\hline \multicolumn{2}{|l|}{ Quality of life ( $n=346)$} \\
\hline \multicolumn{2}{|l|}{ SF-36v2 } \\
\hline $\begin{array}{l}\text { General health } \\
\text { (Range) }\end{array}$ & $\begin{array}{l}25.35(18.20) \\
(0-84.80)\end{array}$ \\
\hline $\begin{array}{l}\text { Physical functioning } \\
\text { (Range) }\end{array}$ & $\begin{array}{l}53.34(29.3) \\
(0-100)\end{array}$ \\
\hline $\begin{array}{l}\text { Role-physical } \\
\text { (Range) }\end{array}$ & $\begin{array}{l}55.60(28.3) \\
(0-100)\end{array}$ \\
\hline Role-emotional & $49.28(27.2)$ \\
\hline (Range) & $(0-100)$ \\
\hline $\begin{array}{l}\text { Social functioning } \\
\text { (Range) }\end{array}$ & $\begin{array}{l}51.29(25.2) \\
(0-100)\end{array}$ \\
\hline $\begin{array}{l}\text { Bodily pain } \\
\text { (Range) }\end{array}$ & $\begin{array}{l}50.22(27.5) \\
(0-100)\end{array}$ \\
\hline $\begin{array}{l}\text { Vitality } \\
\text { (Range) }\end{array}$ & $\begin{array}{l}30.88(19.0) \\
(0-94)\end{array}$ \\
\hline Mental health & $34.49(18.0)$ \\
\hline (Range) & $(0-95)$ \\
\hline EQ-5D & $0.502(0.22)$ \\
\hline (Range) & $(-0.33$ to 1.00$)$ \\
\hline EQ VAS & $50.86(21.5)$ \\
\hline (Range) & $(0-100)$ \\
\hline
\end{tabular}

Abbreviations: EQ-5D, EuroQoL-5 Dimension descriptive system; EQ VAS, EuroQoL visual analog scale; SD, standard deviation; SF-36v2, 36-item health-related quality of life tool.

other studies, even though it was found to be higher than in the national survey $(11.5 \%$ versus $8.8 \%$ in the national survey), ${ }^{2}$ which may be due to the poor validity of the Thai MINI instrument with regard to diagnosis of dysthymia (Cohen's kappa only 0.2). ${ }^{23}$ In terms of future research, another instrument, such as the Structured Clinical Interview for DSM-IV Axis I Disorders dysthymia module, may be added to the MINI to ensure a better dysthymia diagnosis.

With respect to past history of suicide attempts, our study produced similar results to those of the South Korean study ( $26 \%$ versus $21 \%$, respectively), ${ }^{36}$ both of which are higher scores than those recorded by Claassen et al in the USA $(16.5 \%){ }^{40}$ The rate of recurrent suicidality episodes was found to be higher in our study than in the 2008 national survey in Thailand, ${ }^{2}$ which was carried out in a primary care setting (and for which the results were 2.4\% for the current rate and $0.7 \%$ for the recurrent rate). ${ }^{2}$ This may have been because our research settings were university hospitals, to which patients are often referred from primary care or secondary care hospitals.

In addition, the impact of a family history of depression was found to be similar to that in the study by Kim et al ( $10 \%$ versus $13.8 \%$, respectively), but dissimilar to the Western research undertaken by Nierenberg et al $(55.6 \%)^{41}$ and Yang et al $(25 \%-33 \%){ }^{42}$ It is difficult to draw definitive conclusions from these results; however, we speculate that this discrepancy may reflect the questionnaire used. Family history in the Thai-SAD was assessed using a single question and noncategorized subjects (parents or parents of first-degree family members), which may have limited the reliability of the data when compared with the studies by Nierenberg et al and Yang et al.

As expected, the interpersonal problems' scores in the studied sample were high. This study highlights the association between depression and interpersonal problems, that is commonly found and which, in turn, may make them vulnerable to depression. ${ }^{5,43}$ At the same time, the PSS scores were higher for the depressed patients in this study than for the normal and nondepressed clinical samples in our previous study ${ }^{31}(19.15 \pm 5.3,13.53 \pm 4.56$, and $13.99 \pm 4.27$, respectively), while patients felt they were receiving less support than normal respondents (5.79 \pm 1.0 versus $4.35 \pm 1.3$, respectively)..$^{32}$ Our sample also showed a higher rate of insecure attachment based on the Revised-Experience of Close Relationships score than the normal population and general psychiatric outpatients. ${ }^{30}$ With regard to health-related quality of life, the depressed patients were found to have a poorer quality of life than those who were not depressed, the difference here also being dependent on the severity of depression. ${ }^{44}$

Other researchers have found that depression, in particular somatic depression, is associated with high rates of pain and anxiety (a specific type of anxious somatic depression), and is most commonly found in women. ${ }^{34,45}$

When using the EQ-5D tool, depressed patients were found to have an overall moderate quality of life score, which is consistent with the results obtained using the EQ VAS and SF-36v2. It is important to note that quality of life in this Thai sample was found to be lower among depressed patients than in other studies. ${ }^{45,46}$ Further research is needed in order to examine this finding in more detail. 
Our study has some strengths, in that it was a multicenter study of a "real-life" cohort of depressed patients and all sociodemographic, clinical, and psychosocial variables were assessed. However, the study also has some limitations. First, its design meant that there were inevitable problems related to missing data. Second, there are no standard treatment guidelines available for depression in Thailand, plus antidepressant drugs used at sites are different, depending on the health care delivery system provided of each site. This limits the level of homogeneity in terms of the practice guidelines used.

\section{Conclusion}

Thai-SAD provides sociodemographic and psychosocial data for a group of Thais experiencing new or recurrent episodes of unipolar depression. The unique aspect of this study is that it collected data regarding psychosocial variables, which may act as predictors for recurrence or relapse of depression. Some psychosocial variables, eg, a high perception of stress score, may predict a relapse. Firm conclusions cannot be reached as yet; however, because the complete data set is not yet available, the data here represents a baseline. Our intention is to address this shortfall in a subsequent study.

\section{Acknowledgments}

This study was funded by the National Research Council of Thailand (NRCT), and was coordinated and supported by the Medical Research Network of the Consortium of Thai Medical School (MedResNet). Additional funding for the research was provided by the Faculty of Medicine, Chiang Mai University.

\section{Disclosure}

The authors report no conflicts of interest related to this work.

\section{References}

1. Bundhamcharoen K, Odton P, Phulkerd S, Tangcharoensathien V. Burden of disease in Thailand: changes in health gap between 1999 and 2004. BMC Public Health. 2011;11:53.

2. Kongsuk T. The prevalence of major depressive disorders in Thailand: results from the Epidemiology of Mental Disorders National Survey 2008. Available from: http://www.dmh.go.th/downloadportal/Morbidity/ Depress2551.pdf. Accessed June 13, 2013.

3. Shaver PR, Schachner DA, Mikulincer M. Attachment style, excessive reassurance seeking, relationship processes, and depression. Pers Soc Psychol Bull. 2005;31(3):343-359.

4. Conradi HJ, de Jonge P. Recurrent depression and the role of adult attachment: a prospective and a retrospective study. J Affect Disord. 2009;116(1-2):93-99.

5. Wongpakaran N, Wongpakaran T, van Reekum R. Social inhibition as a mediator of neuroticism and depression in the elderly. BMC Geriatr. 2012;12(1):41.
6. Denollet J. Depression, anxiety, and trait negative affect as predictors of cardiac events: ten years after. Psychosom Med. 2008;70(8): 949-951.

7. Candrian M, Schwartz F, Farabaugh A, Perlis RH, Ehlert U, Fava M. Personality disorders and perceived stress in major depressive disorder. Psychiatry Res. 2008;160(2):184-191.

8. Karaçam Z, Ançel G. Depression, anxiety and influencing factors in pregnancy: a study in a Turkish population. Midwifery. 2009;25(4): 344-356.

9. Baker D, Taylor H. The relationship between condition-specific morbidity, social support and material deprivation in pregnancy and early motherhood. ALSPAC Survey Team. Avon Longitudinal Study of Pregnancy and Childhood. Soc Sci Med. 1997;45(9):1325-1336.

10. Ross LE, Sellers EM, Gilbert Evans SE, Romach MK. Mood changes during pregnancy and the postpartum period: development of a biopsychosocial model. Acta Psychiatr Scand. 2004;109(6):457-466.

11. Webster J, Linnane JW, Dibley LM, Hinson JK, Starrenburg SE, Roberts JA. Measuring social support in pregnancy: can it be simple and meaningful? Birth. 2000;27(2):97-101.

12. Mckee MD, Cunningham M, Jankowski KR, Zayas L. Health-related functional status in pregnancy: relationship to depression and social support in a multi-ethnic population. Obstet Gynecol. 2001;97(6): 988-993.

13. Dysvik E, Lindstrøm TC, Eikeland OJ, Natvig GK. Health-related quality of life and pain beliefs among people suffering from chronic pain. Pain Manag Nurs. 2004;5(2):66-74.

14. Han K, Lee P, Lee S, Park E. Factors influencing quality of life in people with chronic illness in Korea. J Nurs Scholarsh. 2003;35(2):139-144.

15. Arkar H, Sari O, Fidaner H. Relationships between quality of life, perceived social support, social network, and loneliness in a Turkish sample. Yeni Symposium. 2004;42(1):20-27.

16. Avicenna M, Abdul Rahman WR. The correlation of health related quality of life with psychological distress, social support and cognitive coping in chronic pain patients. Paper presented at the 4th International Postgraduate Research Colloquium- IPRC2007. International Journal of Behavioral Science. 2008;3(1):31-44.

17. Klein DN, Schwartz JE, Rose S, Leader JB. Five-year course and outcome of dysthymic disorder: a prospective, naturalistic follow-up study. Am J Psychiatry. 2000;157(6):931-939.

18. Goldney RD, Fisher LJ. Double depression in an Australian population. Soc Psychiatry Psychiatr Epidemiol. 2004;39(11):921-926.

19. Rhebergen D, Beekman AT, Graaf R, et al. The three-year naturalistic course of major depressive disorder, dysthymic disorder and double depression. J Affect Disord. 2009;115(3):450-459.

20. Kongsakon R, Udomsubpayakul U, Buranapichet U, Presertchai R. Clinical response of depressive patients in a Thai psychiatric care setting. J Med Assoc Thai. 2005;88(8):1110-1114.

21. Angermeyer MC, Holzinger A, Matschinger H, Stengler-Wenzke K. Depression and quality of life: results of a follow-up study. Int J Soc Psychiatry. 2002;48(3):189-199.

22. Sheehan D, Lecrubier Y, Sheehan K, et al. The Mini-International Neuropsychiatric Interview (MINI): the development and validation of a structured diagnostic psychiatric interview for DSM-IV and ICD-10. J Clin Psychiatry. 1998;59 Suppl 20:22-33.

23. Kittirattanapaiboon P, Khamwongpin M. The validity of the Mini International Neuropsychiatric Interview (MINI)- Thai version. J Ment Health Thai. 2005;13(3):126-136.

24. Lotrakul M, Sukkhanit P, Sukying C. The development of Hamilton Rating Scale for Depression - Thai version. J Psychiatr Assoc Thai. 1996;41:235-246.

25. Lotrakul M, Sukanich P. Development of the Thai Depression Inventory. J Med Assoc Thai. 1999;82(12):1200-1207.

26. (Thailand) TTBF. Thai Geriatric Depression Scale. Siriraj Hosp Gaz. 1994;46:1-9.

27. EuroQol Group. A new facility for the measurement of health-related quality of life. Health Policy. 1990;16(3):199-208.

28. Tongsiri S, Cairns J. Estimating population-based values for EQ-5D health states in Thailand. Value Health. 2011;14(8):1142-1145. 
29. Wongpakaran T, Wongpakaran N, Sirithepthawee U, et al. Interpersonal problems among psychiatric outpatients and non-clinical samples. Singapore Med J. 2012;53(7):481-487.

30. Wongpakaran T, Wongpakaran N. A short version of the revised 'experience of close relationships questionnaire': investigating non-clinical and clinical samples. Clin Pract Epidemiol Ment Health. 2012;8:36-42.

31. Wongpakaran N, Wongpakaran T. The Thai version of the PSS-10: an investigation of its psychometric properties. Biopsychosoc Med. 2010;4:6.

32. Wongpakaran T, Wongpakaran N, Ruktrakul R. Reliability and validity of the Multidimensional Scale of Perceived Social Support (MSPSS): Thai version. Clin Pract Epidemiol Ment Health. 2011;7:161-166.

33. Wongpakaran N, Wongpakaran T. A revised Thai multi-dimensional scale of perceived social support. Span J Psychol. 2012;15(3):1503-1509.

34. Silverstein B. Gender differences in the prevalence of somatic versus pure depression: a replication. Am J Psychiatry. 2002;159(6):1051-1052.

35. Romans SE, Tyas J, Cohen MM, Silverstone T. Gender differences in the symptoms of major depressive disorder. JNerv Ment Dis. 2007;195(11): 905-911.

36. Kim TS, Jeong SH, Kim JB, et al. The clinical research center for depression study: baseline characteristics of a Korean long-term hospital-based observational collaborative prospective cohort study. Psychiatry Investig. 2011;8(1):1-8.

37. Jang Y, Kim G, Chiriboga DA. Gender differences in depressive symptoms among older Korean American immigrants. Soc Work Public Health. 2011;26(1):96-109.

38. Kornstein SG, Schatzberg AF, Thase ME, et al. Gender differences in chronic major and double depression. J Affect Disord. 2000; 60(1):1-11.
39. Lin HW, Hsu HC, Chang MC. Gender differences in the association between stress trajectories and depressive symptoms among middle aged and older adults in Taiwan. J Women Aging. 2011;23(3):233-245.

40. Claassen CA, Trivedi MH, Rush AJ, et al. Clinical differences among depressed patients with and without a history of suicide attempts: findings from the STAR*D trial. J Affect Disord. 2007;97(1-3):77-84.

41. Nierenberg AA, Trivedi MH, Fava M, et al. Family history of mood disorder and characteristics of major depressive disorder: a STAR*D (sequenced treatment alternatives to relieve depression) study. J Psychiatr Res. 2007;41(3-4):214-221.

42. Yang F, Li Y, Xie D, et al. Age at onset of major depressive disorder in Han Chinese women: relationship with clinical features and family history. J Affect Disord. 2011;135(1-3):89-94.

43. Wongpakaran T, Wongpakaran N. How the interpersonal and attachment styles of therapists impact upon the therapeutic alliance and therapeutic outcomes. J Med Assoc Thai. 2012;95(12):1583-1592.

44. Gerhards SA, Evers SM, Sabel PW, Huibers MJ. Discrepancy in rating health-related quality of life of depression between patient and general population. Qual Life Res. 2011;20(2):273-279.

45. Lai CH. Major depressive disorder: gender differences in symptoms, life quality, and sexual function. J Clin Psychopharmacol. 2011;31(1): 39-44.

46. Jonkers CC, Lamers F, Evers SM, Bosma H, Metsemakers JF, Van Eijk JT. Economic evaluation of a minimal psychological intervention in chronically ill elderly patients with minor or mild to moderate depression: a randomized trial (the DELTA-study). Int J Technol Assess Health Care. 2009;25(4):497-504.
Neuropsychiatric Disease and Treatment

\section{Publish your work in this journal}

Neuropsychiatric Disease and Treatment is an international, peerreviewed journal of clinical therapeutics and pharmacology focusing on concise rapid reporting of clinical or pre-clinical studies on a range of neuropsychiatric and neurological disorders. This journal is indexed on PubMed Central, the 'PsycINFO' database and CAS.

\section{Dovepress}

The manuscript management system is completely online and includes a very quick and fair peer-review system, which is all easy to use. Visit http://www.dovepress.com/testimonials.php to read real quotes from published authors. 